\title{
Peripheral Metabolism of Intact Parathyroid Hormone
}

\author{
ROLE OF LIVER AND KIDNEY AND THE EFFECT \\ OF CHRONIC RENAL FAILURE
}

\author{
K. A. Hruska, A. Korkor, K. Martin, and E. Slatopolsky, The Renal Divisions, \\ Department of Medicine, The Jewish Hospital of St. Louis, Washington \\ University, St. Louis, Missouri 63110
}

A B S T R A C T The plasma disappearance rate (metabolic clearance rate) of administered intact parathyroid hormone (intact PTH) was analyzed in awake dogs with indwelling hepatic and renal vein catheters. The metabolic clearance rate (MCR) of intact PTH was found to be very rapid, $21.6 \pm 3.1 \mathrm{ml} / \mathrm{min}$ per $\mathrm{kg}$ in 11 normal dogs. The liver accounted for the greatest fraction of the MCR of intact PTH $(61 \pm 4 \%)$ by virtue of an arterial minus venous $(\mathrm{a}-\mathrm{v})$ difference across the liver of $45 \pm 3 \%$. The renal uptake of intact PTH accounted for $31 \pm 3 \%$ of the MCR of intact PTH. The renal a - v difference for intact PTH of $29 \pm 2 \%$ was significantly greater than the filtration fraction indicating renal uptake of intact PTH at sites independent of glomerular filtration. Together, the hepatic and renal clearances of intact PTH accounted for all but a small fraction of the MCR of intact PTH. The MCR of intact PTH, rendered biologically inactive by oxidation, was markedly decreased to $8.8 \pm 1 \mathrm{ml} / \mathrm{min}$ per $\mathrm{kg}$. The a $-\mathrm{v}$ difference of oxidized intact PTH was reduced both in the liver and kidney. These data suggested that the high uptake rates of intact PTH are dependent, at least in part, upon sites recognizing only biologically active PTH.

Chronic renal failure (CRF) decreased the MCR of intact PTH to $11.3 \pm 1.3 \mathrm{ml} / \mathrm{min}$ per $\mathrm{kg}(n=10)$. Both the hepatic and renal $a-v$ differences of intact PTH were reduced in dogs with $\mathrm{CRF}$. This resulted in reductions in the hepatic and renal clearances of intact PTH. These studies identify the liver as a major extrarenal site of PTH metabolism affected by CRF. They suggest that

Presented in part at the Annual Meeting of the American Federation for Clinical Research, San Francisco, Calif. (1978. Clin. Res. 26: 466A), and at the 12th Annual Meeting of the American Society of Nephrology, Boston, Mass. (1979. American Society of Nephrology Abstracts. 97A).

Dr. Hruska is an Established Investigator of the American Heart Association.

Received for publication 1 May 1980 and in revised form 13 November 1980.
CRF impairs the function of the major uptake sites involved in intact PTH metabolism.

\section{INTRODUCTION}

In recent years, our knowledge of the peripheral metabolism of parathyroid hormone $(\mathrm{PTH})^{1}$ has been greatly enhanced. Circulating PTH has been shown to be a heterogenous mixture of intact hormone (PTH 1-84) and hormone fragments (1-7). In addition, work by several authors $(3,8-11)$ has demonstrated different specificities among the target organs for the form of PTH that each organ removes from the circulation. For instance, several authors have demonstrated that intact PTH is removed from the circulation by the liver $(3,4,8,9)$. A previous report from our laboratory suggested that hepatic uptake of PTH is specific for intact PTH 1-84, whereas no hepatic uptake of carboxy terminal PTH fragments or synthetic bPTH 1-34 was demonstrable (9). In contrast, specific uptake mechanisms for the synthetic amino terminal fragment of PTH (syn b-PTH 1-34) were demonstrated in the isolated perfused canine bone in vitro but only minor uptake rates of intact hormone were demonstrable (11). The kidney appears to have specific uptake mechanisms for both the intact hormone and amino terminal fragment of PTH at sites independent of glomerular filtration (10). Yet, the kidney also nonspecifically removes all forms of immunoreactive PTH (i-PTH) through the mechanism of glomerular filtration and tubular reabsorption $(10,12)$. This latter process appears to be a nonspecific small peptide cleavage mechanism important in protein catabolism $(13,14)$.

In the face of these advances, our quantitative

\footnotetext{
${ }^{1}$ Abbreviations used in this paper: a - v, arterial minus venous; CRF, chronic renal failure; ICG, Indocyanine Green MCR, metabolic clearance rate; PAH, paraminohippurate; PTH, parathyroid hormone.
} 
knowledge of the metabolism of intact PTH remains inadequate. The metabolism of the hormone is thought to be rapid, judging from the rapid initial rates of disappearance of PTH following its addition to the circulation $(1,3,15,16)$. However, formal quantitation of the metabolic clearance rate (MCR) of intact PTH has been determined only in calves (16). Thus far, the estimates of the contributions of individual organs to the MCR of intact PTH fail to account for significant portions of the $\operatorname{MCR}(3,17)$. The liver has been identified as having the greatest uptake rate for intact hormone $(3,9,17)$. Studies by D'Amour et al. (17) suggest that most of hepatic PTH uptake is localized to Kupffer cells, and that hepatic cleavage of intact PTH and production of C-terminal fragments can be attributed to this cell type. However, data from our laboratory $(18)$ and others $(19,20)$ suggest that PTH has important physiologic effects on hepatic glucose and amino acid metabolism which are probably a function of the hepatocytes and not explainable by PTH uptake by Kupffer cells alone. This may indicate that there are additional sites of PTH uptake in the liver besides the demonstrated binding to Kupffer cells.

Our earlier studies in dogs with chronic renal failure (CRF) suggested that $\mathrm{CRF}$ results in a reduction not only of renal PTH metabolism, but also its metabolism at an extrarenal site (5). Our initial attempts to identify this site failed because of the limitation of the C-terminal immunoassay being used. We undertook the present studies for several purposes: first, to provide further quantitation of the MCR of intact PTH; second, to examine the uptake of intact PTH by the liver and the kidney comparing the uptake of biologically active and oxidized hormone; third, to determine individual organ contributions to the total MCR of intact PTH; and finally, to examine the effects of CRF on the metabolism of intact hormone in order to identify the site of impaired extrarenal PTH metabolism in CRF.

\section{METHODS}

Preparation of dogs. Mongrel dogs weighing $14-28 \mathrm{~kg}$ were fed a standard high protein Purina dog chow (RalstonPurina Co., St. Louis, Mo.) and had free access to water. In those dogs in whom the hepatic metabolism of PTH was studied, catheters were placed in the portal vein and the left common hepatic vein as described previously $(9)$. The method of hepatic vein catheterization was originally described by Shoemaker et al. (21). Catheter patency was maintained by intermittent filling with heparin. After surgery, the dogs were followed closely for resumption of normal dietary and bowel habits. The shortest time interval after surgery to study was $72 \mathrm{~h}$. Dogs that were not eating full rations or having normal formed stools were not studied. In those dogs in whom the metabolism of PTH by the kidney was studied, polyethylene catheters were advanced from the inferior vena cava into the renal vein at laparotomy. The catheters were filled with heparin, and the studies were performed $24-48 \mathrm{~h}$ following surgery.
CRF was induced by $75-85 \%$ infarction of the left kidney followed by contralateral nephrectomy as previously described (5). After induction of renal failure, the dogs were stabilized for at least $4 \mathrm{wk}$ before placement of hepatic, portal, or renal vein catheters and performance of PTH metabolism studies.

Study protocol. Dogs were studied awake and resting in a sling after a 12 -h fast. The femoral artery was catheterized by the Seldinger technique (22) and a polyethylene catheter was advanced into the aorta to the approximate level of the celiac axis or the renal artery. A hind leg vein catheter was placed for infusions of solutions and injections of PTH. During studies of hepatic PTH metabolism, hepatic plasma flow was measured by the previously reported methods ( 9 , 23), using constant infusions of Indocyanine Green (ICG; Hynson, Westcott, Dunning, Inc., Baltimore, Md.). The hepatic arterial venous difference $(a-v)$ for ICG also served as a marker for adequacy of hepatic venous sampling to exclude contamination of samples with inferior vena cava blood (23). In studies of the renal metabolism of intact PTH, glomerular filtration rate was measured by exogenous creatinine clearance and renal plasma flow was measured by the extraction and clearance of paraminohippurate (PAH). PAH extraction also served as a marker of adequacy of renal vein sampling. In both types of studies, base-line periods were conducted for determination of catheter function and renal and hepatic plasma flow determinations. Then constant infusions of bovine PTH (b-PTH 1-84) were begun following bolus injections at $5-10 \mu \mathrm{g}$ at a rate of $0.2-0.7 \mu \mathrm{g} / \mathrm{min}$. This infusion rate was found to maintain immunoreactive intact PTH in the plasma at a concentration of $0.5-5.2 \mathrm{ng} / \mathrm{ml}$. These levels are lower than those at which we have reported circulating amino terminal fragments following injections of intact b-PTH 1-84 in dogs (5, 9). Equilibration of PTH levels for $50 \mathrm{~min}$ was allowed before experimental periods were begun. Then 5-10 experimental samples were obtained from the aorta and/or the renal, hepatic, and portal veins simultaneously. PTH infusions were administered through the hind leg vein catheter. The PTH was added to dog plasma obtained from each animal before the infusion and was kept under ice during the infusion. The use of the dog plasma as a carrier for the PTH was designed to limit loss of PTH through adsorption to the infusion apparatus (24). Concentration of PTH in the infusate was measured at the beginning, middle, and end of the infusion and remained stable throughout the duration of the infusions.

Source of PTH. The b-PTH 1-84 used in these studies was obtained from three lots of hormone prepared from extracts of bovine parathyroid glands. PTH was purified according to the method of Hamilton et al. (25), except that final purification by carboxy methyl cellulose ion exchange chromatography was performed using a linear gradient of ammonium acetate in $8 \mathrm{M}$ urea as the elution buffer. Hormone preparations so isolated revealed single peaks of radioimmunoassayable PTH-like activity when subjected to polyacrylamide gel electrophoresis (Fig. 1A). The biological activity of the preparations was $2,000 \mathrm{U} / \mathrm{mg}$ in a renal cortical adenylate cyclase assay (26). The standard, against which the biological activity of our preparations was compared, was prepared and standardized by Hamilton et al. (25). Synthetic bovine PTH 1-34 (syn b-PTH 1-34) was obtained from Beckman Instruments, Inc., Spinco Div., Palo Alto, Calif.). Oxidized b-PTH 1-84 was prepared by dissolving lyophilized $50-\mu \mathrm{g}$ aliquots of b-PTH 1-84 in $60 \gamma$ of $150 \mathrm{mM}$ acetic acid and adding $40 \mu \mathrm{l}$ of $30 \%$ hydrogen peroxide. After incubation at $37^{\circ} \mathrm{C}$ for $45 \mathrm{~min}$, the reaction mixture was lyophilized. The $\mathrm{H}_{2} \mathrm{O}_{2}$ oxidized b-PTH 1-84 was identical in its elution position on polyacrylamide gels to biologically active b-PTH $1-84$, and it had no significant biological activity in a renal 


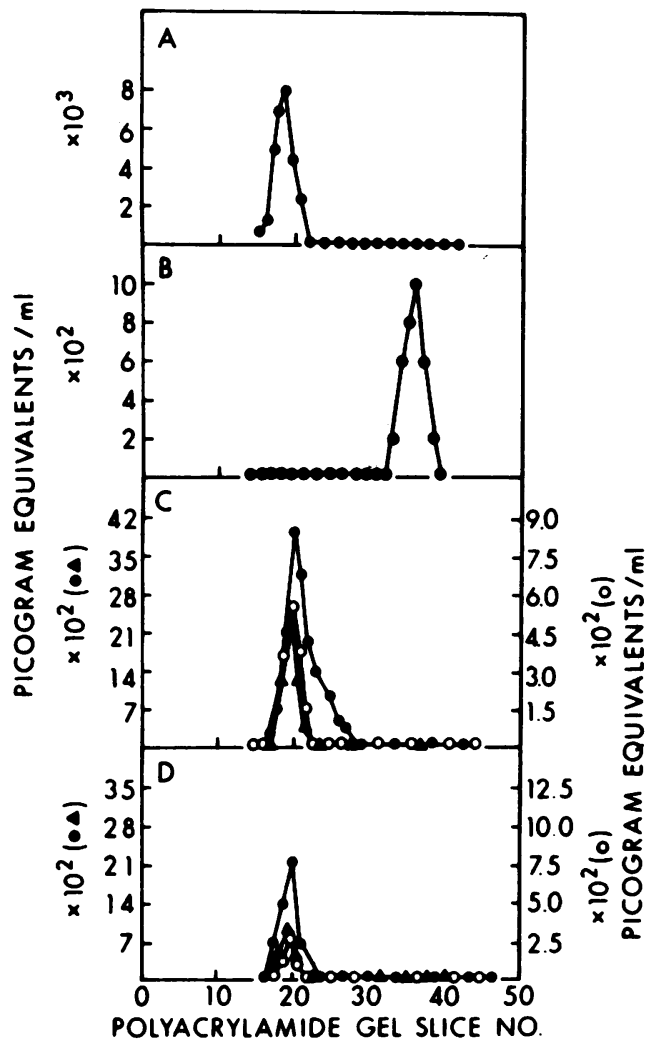

FIGURE 1 Radioimmunoassayable PTH eluted from gel slices following polyacrylamide gel electrophoresis of b-PTH $1-84$, syn b-PTH 1-34, and plasma samples obtained during PTH infusion. Panel A, b-PTH 1-84 infused into the dogs and used as the radioimmunoassay standard; panel B,syn b-PTH 1-34; panel C, i-PTH in arterial plasma concentrates obtained from normal dog No. 5 in Table I (O), and dog No. 3 with CRF ( $\Delta$ ). Also, i-PTH in unconcentrated arterial plasma from dog No. 1 with CRF (O); panel D, matching hepatic vein samples to those shown in panel $\mathrm{C}$.

cortical adenylate cyclase assay (26). It also failed to induce phosphaturia in the dogs studied in the present studies.

Radioimmunoassay methods. iPTH levels in plasma, infusates, and polyacrylamide gel eluates were determined by radioimmunoassay methods described in detail previously $(5,9)$. The CH9N antiserum specific for the amino terminal portion of b-PTH 1-84 was used in the determinations of immunoassayable intact PTH. The amino terminal specificity of this antiserum stems from the fact that it was produced by a cockerel immunized with syn b-PTH 1-34. The antiserum was used in a dilution of $1: 25,000$ in these studies. The displacement of ${ }^{125} \mathrm{I}-\mathrm{b}-\mathrm{PTH}$ 1-84 binding to the CH9N antiserum by unlabeled syn b-PTH 1-34, b-PTH 1-84, and oxidized b-PTH 1-84 is shown in Fig. 2. Nearly complete displacement of the iodinated tracer was produced by 130 fmol of syn b-PTH 1-34 and 147 fmol b-PTH 1-84. Oxidized b-PTH 1-84 was not different from b-PTH 1-84 in displacing ${ }^{125}$ I-b-PTH 1-84 from the CH9N antiserum. For determination of immunoreactive intact PTH, ${ }^{125}$ I-b-PTH 1-84 prepared as previously described $(5,9)$, served as the radioactive tracer and b-PTH 1-84 as the standard curve.

Polyacrylamide gel electrophoresis. As mentioned above, the infusion rates of b-PTH 1-84 were designed to keep

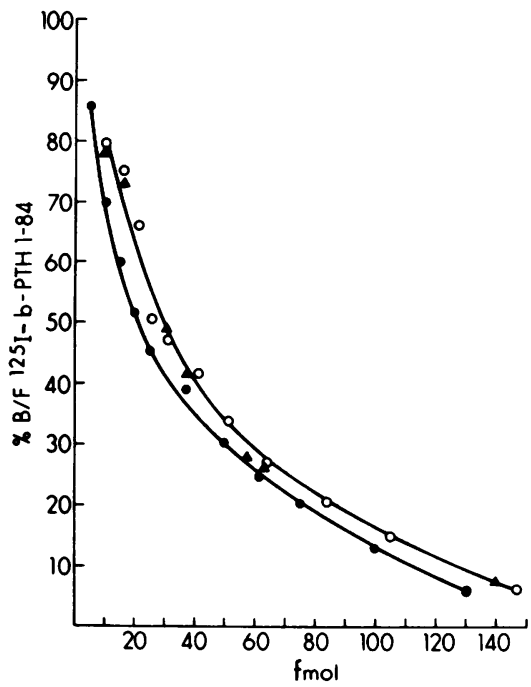

FIGURE 2 Displacement of ${ }^{125}$ I-b-PTH 1-84 bound to the CH9N antiserum. The data is plotted as the ratio of bound counts to free counts vs. increasing amounts of syn b-PTH 1-34 (O), b-PTH 1-84 (O), or oxidized (ox) b-PTH 1-84 ( $\triangle$ ).

i-PTH levels below those where amino terminal fragments would be detectable in the plasma samples. To confirm that amino terminal fragments were not contributing significantly to i-PTH levels in these studies, plasma samples from each study were subjected to polyacrylamide gel electrophoresis. Eluates from the gels were subjected to radioimmunoassay for detection of amino terminal fragments. In addition, samples from the polyacrylamide gel eluates were also subjected to $\mathrm{C}$-terminal radioimmunoassay for comparison of the immunoreactive forms of C-terminal PTH in the gel eluates. In these assays, the $\mathrm{CH} 9$ antiserum, a $\mathrm{C}$ terminal antiserum previously described $(5,9)$, was used as the binding ligand and ${ }^{125} \mathrm{I}-\mathrm{b}-\mathrm{PTH} \quad 1-84$ as the radioiodinated tracer and b-PTH 1-84 as the standard.

Gel electrophoresis was performed in a tube gel apparatus using $10 \%$ (wt/vol) acrylamide and $1 \%$ (wt/vol) bis-acrylamide gels in $8 \mathrm{M}$ urea according to the method of Riesfield et al. (27), as previously described (26). 2-mm slices of the gels were agitated for $24 \mathrm{~h}$ in $0.1 \mathrm{M}$ sodium barbital buffer, $\mathrm{pH}$ 8.6 containing $10 \%$ plasma and $500 \mathrm{U} / \mathrm{ml}$ of Trasylol (FBA Pharmaceuticals, New York), before immunoassay of PTH. The extraction efficiency from the gels was 75-85\% for both b-PTH 1-84 and syn b-PTH 1-34. As shown in Fig. 1, polyacrylamide gel electrophoresis of plasma samples revealed iPTH eluting from the gels only in the area of the b-PTH 1-84 standard. The C-terminal immunoassays of the same samples (data not shown) revealed multiple fragment peaks besides the intact hormone peak. These results indicate that the radioimmunoassay system using the $\mathrm{CH} 9 \mathrm{~N}$ antiserum, b-PTH 1-84 standard, and ${ }^{125}$ I-b-PTH 1-84 tracer indeed represented an immunoassay of intact PTH at the levels of PTH obtained in the present studies.

Concentration of plasma samples. Plasma intact PTH levels obtained in several studies were too low for direct application to polyacrylamide gels since sample volume in the gels system was limited (maximum, $100 \mu \mathrm{l}$ ). To check for immunoassayable amino terminal fragments in these plasma samples, they were concentrated prior to undergoing polyacrylamide gel electrophoresis. Concentration of PTH was performed by the technique of adsorption of PTH to microfine silica (Quso G-32) and elution from the silica 
by acetone/acetic acid. Quso, $2.5 \mathrm{mg} / \mathrm{ml}$ plasma, was added to each sample to be concentrated. Plasma was then centrifuged at $2,500 \mathrm{rpm}$ at $5^{\circ} \mathrm{C}$ for $10 \mathrm{~min}$ and the supernate was discarded. The precipitate was washed with $2 \mathrm{ml}$ of distilled water and recentrifuged. Then, $0.5 \mathrm{ml}$ of $30 \%$ acetone, $0.2 \%$ acetic acid, and $1.5 \mathrm{ml}$ of $\mathrm{H}_{2} \mathrm{O}$ were added to the precipitate. After mixing, the samples were recentrifuged and the supernates were lyophilized and reconstituted in 200 $\mu \mathrm{l}$ of $0.1 \mathrm{M}$ acetic acid in $8 \mathrm{M}$ urea for gel electrophoresis. Known amounts of b-PTH 1-84 and syn b-PTH 1-34 were added to hypoparathyroid plasma and also subjected to the adsorption technique for determination of recoveries. 60 $80 \%$ of both peptides were recovered in the lyophilized eluates from the Quso. The plasma samples designated by $\checkmark$ and $\Delta$ in Fig. 1 were concentrated 10 -fold by this technique before polyacrylamide gel electrophoresis. In no plasma sample was there detectable immunoassayable PTH $(\mathrm{CH} 9 \mathrm{~N}$ antiserum) in gel eluates that migrated within the area of syn b-PTH 1-34. The pattern of C-terminal immunoassayable PTH in the gel eluates was similar to the patterns of nonconcentrated plasma samples, indicating recovery of all the fragment forms that bound to the $\mathrm{CH} 9$ antiserum.

Chemical determinations. Constant infusions of ICG were used to measure hepatic plasma flow and to check for adequacy of hepatic venous sampling. The techniques of ICG infusion and measurement have been reported previously in detail (9). Exogenous creatinine infusions were used to determine glomerular filtration rate. Creatinine concentrations were measured by the Jaffe reaction as described by Folin (28) and adapted for the Technicon autoanalyzer (Technicon Instruments, Inc., Tarrytown, N. Y.). Infusions of PAH were utilized to determine renal plasma flow and the adequacy of renal venous sampling. PAH concentrations were determined by the method of Harvey and Brothers (29), as adapted for the Technicon autoanalyzer.

Calculations. Hepatic plasma flow was calculated by dividing the MCR of ICG (ICG infusion rate/arterial ICG concentration) by the hepatic a - v difference of ICG. Renal plasma flow was calculated by the Wolff modification of the Fick principle (30) using clearances of PAH. Filtration fraction was determined as the ratio of creatinine clearance and renal plasma flow. The percent hepatic and renal $\mathrm{a}-\mathrm{v}$ difference of intact PTH was determined by dividing the $a-v$ concentration difference of intact PTH by the arterial intact PTH concentration. MCR of intact PTH was determined by dividing the infusion rate of intact PTH in $\mathrm{ng} / \mathrm{ml}$ by the stable arterial PTH concentration. Endogenous PTH was detectable in only one of the CRF dogs and these levels were subtracted from the levels determined during PTH 1-84 infusion The renal and hepatic clearances of PTH were determined by multiplying the percent $\mathrm{a}-\mathrm{v}$ difference of intact PTh by the plasma flow for each organ. Statistical differences between groups was assessed by Student's $t$ test.

\section{RESULTS}

The metabolism of intact PTH in dogs with hepatic vein and portal vein catheters is shown in Table I. The arterial plasma intact PTH levels listed represent the mean of at least five determinations, deviating by no more than $5 \%$ from the mean level. Thus, these levels fulfill the criteria for determination of MCR by the constant infusion technique $(31,32)$. The mean MCR of intact PTH in the normal dogs with hepatic vein catheters was $19.7 \pm 1.1 \mathrm{ml} / \mathrm{min}$ per $\mathrm{kg}$. The hepatic handling of ICG revealed adequate extraction in all instances. The data shown are the mean of at least five determinations in each animal. Paired arterial and hepatic venous plasma samples that displayed less than $10 \%$ a $-\mathrm{v}$

TABLE I

Metabolism of Intact PTH: Contribution of the Liver

\begin{tabular}{|c|c|c|c|c|c|c|c|}
\hline & $\begin{array}{l}\text { Plasma } \\
\text { i-PTH }\end{array}$ & $\begin{array}{l}\text { MCR intact } \\
\text { hormone }\end{array}$ & $\begin{array}{c}\text { Hepatic ICG } \\
\mathrm{A}-\mathrm{V} \text { difference }\end{array}$ & HPF & $\begin{array}{c}\text { Hepatic i-PTH } \\
\text { A - V difference }\end{array}$ & $\mathrm{HC}$ & $\mathrm{HC} / \mathrm{MCR}$ \\
\hline Normals & ngleq per $m l$ & $\mathrm{ml} / \mathrm{min}$ per $\mathrm{kg}$ & $\%$ & $\mathrm{ml} / \mathrm{min}$ per $\mathrm{kg}$ & $\%$ & $\mathrm{ml} / \mathrm{min}$ per $\mathrm{kg}$ & $\%$ \\
\hline 1 & 1.26 & 20.7 & 20 & 26.1 & 54 & 14.1 & 68 \\
\hline 2 & 1.59 & 18.5 & 12 & 30.4 & 44 & 13.4 & 72 \\
\hline 3 & 1.36 & 17.9 & 13 & 24.8 & 41 & 10.2 & 58 \\
\hline 4 & 1.01 & 18.1 & 10 & 22.4 & 45 & 10.1 & 52 \\
\hline 5 & 3.40 & 23.6 & 13 & 30.0 & 42 & 12.6 & 53 \\
\hline 6 & 2.20 & 19.4 & 15 & 28.4 & 41 & 11.6 & 60 \\
\hline Mean & & 19.7 & 14 & 27.0 & 45 & 12.0 & 61 \\
\hline SEM & & 1.1 & 2 & 1.4 & 3 & 0.8 & 4 \\
\hline CRF & & & & & & & \\
\hline 1 & 3.90 & 12.8 & 12 & 27.9 & 38 & 10.6 & 83 \\
\hline 2 & 0.90 & 13.0 & 14 & 29.7 & 30 & 8.9 & 68 \\
\hline 3 & 2.07 & 7.7 & 10 & 23.8 & 24 & 5.7 & 74 \\
\hline 4 & 1.08 & 14.2 & 16 & 35.2 & 21 & 7.4 & 52 \\
\hline 5 & 1.50 & 11.5 & 13 & 29.2 & 28 & 8.2 & 69 \\
\hline Mean & & 11.8 & 13 & 29.2 & 28 & 8.2 & 69 \\
\hline SEM & & 1.4 & 1 & 1.8 & 4 & 1.0 & 7 \\
\hline$P(\mathrm{~N}$ vs. $\mathrm{CRF})$ & & 0.01 & NS & NS & 0.005 & 0.01 & NS \\
\hline
\end{tabular}

HC, hepatic clearance; HC/MCR, hepatic contribution to total MCR. 
difference for ICG were not included in the radioimmunoassays for PTH. The hepatic a - $\mathrm{v}$ difference of ICG and the calculated hepatic plasma flow in the normal dog is similar to results previously published from our laboratory (9) and others (23). The $a-v$ difference of intact PTH across the liver was $45 \pm 3 \%$. The hepatic clearance of intact PTH was $12.0 \pm 0.8 \mathrm{ml} / \mathrm{min}$ per $\mathrm{kg}$, and this represented $61 \pm 4 \%$ of the total MCR. Thus, the MCR of intact PTH is very rapid, and the liver accounts for the majority of its removal rate from the plasma.

Attempts were made to reduce infusion rates of PTH in studies of dogs with CRF, such that the plasma intact PTH levels attained did not substantially differ from those attained in normal dogs. In dogs with CRF, the MCR of intact PTH was reduced to $11.8 \pm 1.4$ $\mathrm{ml} / \mathrm{min}$ per $\mathrm{kg}$. The hepatic handling of ICG by the dogs with CRF was not significantly different from normal, and the calculated hepatic flow did not differ from values seen in normal dogs. The hepatic a $-v$ difference of intact PTH was significantly depressed in dogs with $\mathrm{CRF}$ to $28 \pm 4(P<0.005$ compared with normal dogs). The reduction in the percent extraction of intact PTH by the liver resulted in a reduction of hepatic PTH clearance to $8.2 \pm 1.0 \mathrm{ml} / \mathrm{min}$ per $\mathrm{kg}$. This indicates that CRF not only reduces the renal metabolism of PTH, but also reduces the hepatic metabolism of intact PTH. The hepatic contribution to the total MCR in dogs with CRF was $69 \pm 7 \%$, not significantly different from the value observed in normal animals. Thus, the decrease in $\mathrm{a}-\mathrm{v}$ difference for PTH by the liver in CRF impairs the ability of the liver to serve as a compensatory organ for the decreased clearance of PTH by the kidney in this condition. There was no significant detectable $\mathrm{a}-\mathrm{v}$ difference for PTH between arterial and portal venous plasma in either normal dogs or dogs with CRF (data not shown). Thus, significant uptake of intact PTH by splanchnic organs was not detectable in these studies.

The metabolism of intact PTH in dogs with renal vein catheters is shown in Table II. Plasma intact PTH levels in these animals were within the range of those portrayed in Table I. The MCR of intact PTH in these normal dogs was $24 \pm 3.9 \mathrm{ml} / \mathrm{min}$ per $\mathrm{kg}$, not significantly different from the normal animals portrayed in Table I. The mean values for PAH extraction, renal plasma flow, creatinine clearance, and $a-v$ difference for intact PTH represent the mean of at least five determinations obtained during the constant infusions of b-PTH 1-84. The a - v difference for intact

TABLE II

Metabolism of Intact PTH: Contribution of the Kidney

\begin{tabular}{|c|c|c|c|c|c|c|c|c|c|}
\hline & $\begin{array}{l}\text { Plasma } \\
\text { i-PTH }\end{array}$ & $\begin{array}{l}\text { MCR intact } \\
\text { hormone }\end{array}$ & $\begin{array}{c}\text { Renal } \\
\text { PAH } \\
\mathbf{A}-\mathbf{V} \\
\text { difference }\end{array}$ & RPF & $\mathrm{CrCl}$ & FF & $\begin{array}{c}\text { Renal } \\
\text { i-PTH } \\
\text { A-V } \\
\text { difference }\end{array}$ & $\mathrm{RC}$ & $\mathrm{RC} / \mathrm{MCR}$ \\
\hline Normals & ngleq per ml & ml/min per $k g$ & $\%$ & ml/min per $\mathrm{kg}$ & $\mathrm{ml} / \mathrm{min}$ per $\mathrm{kg}$ & $\%$ & $\%$ & $\mathrm{ml} / \mathrm{min}$ per $\mathrm{kg}$ & $\%$ \\
\hline 1 & 0.54 & 28.2 & 79 & 31.5 & 6.2 & 20 & 30 & 9.5 & 34 \\
\hline 2 & 0.95 & 21.5 & 76 & 24.1 & 5.2 & 22 & 25 & 6.0 & 28 \\
\hline 3 & 2.51 & 16.1 & 85 & 20.0 & 4.0 & 20 & 25 & 5.0 & 31 \\
\hline 4 & 0.64 & 36.9 & 68 & 22.2 & 4.7 & 21 & 37 & 8.2 & 22 \\
\hline 5 & 1.85 & 17.1 & 70 & 24.7 & 4.9 & 20 & 29 & 7.1 & 42 \\
\hline Mean & & 24.0 & 76 & 24.5 & 5.0 & 20.6 & 29 & 7.2 & 31 \\
\hline SE & & 3.9 & 3 & 1.9 & 0.36 & 0.4 & 2 & 0.8 & 3 \\
\hline $\begin{array}{l}P \text { (FF vs. renal } \\
\text { i-PTH difference) }\end{array}$ & & & & \multicolumn{6}{|c|}{$<0.01^{*}$} \\
\hline CRF & & & & & & & & & \\
\hline 1 & 3.70 & 6.2 & 60 & 2.8 & 0.5 & 19 & 19 & 0.5 & 9 \\
\hline 2 & 2.31 & 10.4 & 62 & 6.1 & 1.2 & 20 & 18 & 1.1 & 11 \\
\hline 3 & 2.50 & 11.5 & 64 & 6.0 & 1.2 & 20 & 20 & 1.2 & 10 \\
\hline 4 & 5.2 & 10.7 & 76 & 3.9 & 0.9 & 23 & 22 & 0.9 & 8 \\
\hline 5 & 1.87 & 14.5 & 77 & 4.5 & 1.0 & 22 & 22 & 1.0 & 7 \\
\hline Mean & & 10.7 & 68 & 4.7 & 1.0 & 20.8 & 20.0 & 0.9 & 9 \\
\hline SE & & 1.4 & 4 & 0.6 & 0.1 & 0.7 & 1.0 & 0.1 & 1 \\
\hline$P(\mathrm{~N}$ vs. $\mathrm{CRF})$ & & $<0.02$ & NS & $<0.001$ & $<0.001$ & NS & $\begin{array}{l}<0.005 \\
\mathrm{NS}\end{array}$ & $<0.001$ & $<0.001$ \\
\hline
\end{tabular}

RPF, renal plasma flow; $\mathrm{CrCl}$, creatinine clearance; FF, filtration fraction; RC, renal PTH clearance; RC/MCR, renal contribution to MCR.

* Significance of difference between FF and renal a - v difference intact PTH. 
PTH across the kidney was $29 \pm 2 \%$, a value significantly greater than the filtration fraction of $20.6 \pm 0.4 \%$ $(P<0.01)$. This indicates that the extraction of intact PTH by the normal dog kidney is greater than what could be accounted for by glomerular filtration alone assuming a sieving coefficient of one. However, Kau and Maack (12) have estimated a sieving coefficient of 0.7 for PTH 1-84. This further indicates the significance of the $a-v$ difference of $29 \%$ for intact PTH observed in our studies. The renal clearance of intact PTH was $7.2 \pm 0.8 \mathrm{ml} / \mathrm{min}$ per $\mathrm{kg}$. This value represented $31 \pm 3 \%$ of the total MCR of intact PTH.

In dogs with CRF, the MCR of intact PTH was reduced to $10.7 \pm 1.4 \mathrm{ml} / \mathrm{min}$ per $\mathrm{kg}$, not significantly different from the CRF group shown in Table I. The $a-v$ difference for intact PTH across the chronically diseased kidney was $20 \pm 1 \%$, a value very similar to the filtration fraction and significantly reduced from the $\mathrm{a}-\mathrm{v}$ difference of intact PTH across the normal dog kidney $(P<0.005)$. Thus, the renal clearance of intact PTH in CRF is decreased not only by the decreased renal plasma flow but also by the decrease in the percent $a-v$ difference. This differs from the previously reported results for C-terminal i-PTH (5), where the reduction of renal clearance resulted solely from a reduction in plasma flow while the $\mathrm{a}-\mathrm{v}$ difference for C-terminal i-PTH remained constant. The severe reduction in renal clearance of intact PTH resulted in a reduction in the renal contribution to the total MCR to $9 \pm 1 \%$.

The rapid MCR of intact PTH and the high levels of hepatic and renal intact PTH uptake shown above may, in part, be due to uptake mechanisms recognizing only biologically active PTH. To analyze this possibility, we studied the metabolism of oxidized, biologically inactive intact PTH. PTH, obtained from the same lots used in the studies reported above, was oxidized and infused into five normal dogs with indwelling hepatic (3) or renal (2) vein catheters. These dogs had been used previously in the studies reported in Tables I and II. Infusion of intact PTH had resulted in a reduction of tubular reabsorption of phosphate from a fasting level of 96 to $77 \%$. The infusion of oxidized PTH in the animals resulted in no reduction of the tubular reabsorption of phosphate (Table III). The MCR of oxidized intact PTH was $8.8 \pm 1.0 \mathrm{ml} / \mathrm{min}$ per kg, significantly reduced $(P<0.01)$ from the values for biologically active intact PTH shown in the normal dogs in Tables I and II. This reduction in total MCR was contributed to mainly by a reduction in the hepatic $\mathrm{a}-\mathrm{v}$ difference from a level of $45 \%$ seen in the studies with biologically active PTH to a level of $13 \%$ in the studies with inactive PTH. The reduction in the hepatic $a-v$ difference resulted in a decrease in hepatic clearance from 12.0 to $2.5 \mathrm{ml} / \mathrm{min}$ per $\mathrm{kg}$. During infusion of oxidized PTH into dogs with renal
TABLE III

Effect of Oxidation on the Metabolism of b-PTH 1-84

\begin{tabular}{lccc}
\hline & & $\begin{array}{c}\text { Oxidized } \\
\text { b-PTH } \\
\text { b-PTH } \\
1-84\end{array}$ \\
\hline Change in TRP, & $\%$ & 19 & 0 \\
MCR intact PTH, & ml/min per $k g$ & 21.5 & 8.8 \\
Hepatic a - v difference, & $\%$ & 45 & 13 \\
HC/MCR, & $\%$ & 61 & 38 \\
Renal a - v difference, & $\%$ & 29 & 21 \\
RC/MCR, & $\%$ & 31 & 55 \\
\hline
\end{tabular}

TRP, tubular reabsorption of phosphorus; see Tables I and II for other abbreviations.

vein catheters, the renal PAH extraction was $73 \%$ and the filtration fraction was $21 \%$. The renal a-v difference for oxidized b-PTH $1-84$ was $21 \%$. The reduction in the renal $a-v$ difference of oxidized PTH observed when compared to b-PTH 1-84 resulted in a reduction of renal PTH clearance from $7.2 \mathrm{ml} / \mathrm{min}$ per $\mathrm{kg}$ to $4.9 \mathrm{ml} / \mathrm{min}$ per $\mathrm{kg}$, a value that accounted for $55 \%$ of the total MCR. The apparent increase in the renal contribution to total MCR in the studies with oxidized PTH is similar to the renal contribution to total MCR previously demonstrated by us for C-terminal i-PTH. These data suggest that the body's handling of biologically inactive intact PTH is significantly altered when compared to the handling of biologically active intact hormone. The reduction in the renal $\mathrm{a}-\mathrm{v}$ difference of oxidized PTH was compatible with the major portion of PTH uptake now being accounted for by glomerular filtration and tubular reabsorption as others using oxidized iodinated PTH have suggested (12).

One possible explanation, for the reduced MCR of oxidized b-PTH 1-84, would be association of the oxidized hormone with large plasma proteins that should then decrease the uptake of oxidized PTH from plasma. Nonspecific association of radiolabeled oxidized intact PTH to plasma proteins in column elution buffers is well known $(33,34)$. The plasma samples taken at various times following single injections of both b-PTH 1-84 and oxidized b-PTH 1-84 into dogs, were subjected to gel permeation chromatography using Bio-gel P-100 (Bio-Rad Laboratories, Richmond, Calif.). The elution buffer was $0.15 \mathrm{M}$ ammonium acetate containing $10 \%$ normal dog plasma. The amounts of both b-PTH 1-84 and oxidized b-PTH 1-84 bound to plasma proteins and eluting in the area of the void volume of the column were identical at 5 and $20 \mathrm{~min}$ following injection. They represented a small fraction of the i-PTH eluting in the area of intact hormone. Thus, oxidized PTH in this system did not demonstrate a greater proclivity for plasma protein binding than b-PTH 1-84. 


\section{DISCUSSION}

The studies reported here demonstrate a very rapid MCR of intact PTH. These MCR are compatible with the short (2-5 $\mathrm{min})$ half-time of disappearance for intact PTH suggested by previous studies $(15,16)$. The MCR of intact PTH is also much more rapid than that reported for C-terminal i-PTH $(5,8)$. If the rapidity of the MCR for intact PTH is in part due to uptake of the hormone at binding sites that specifically recognize biologically active hormone, then inactivation of the hormone would be expected to reduce its MCR. Potts et al. (35) have demonstrated that oxidation of PTH results in loss of its biological activity without alteration in its immunologic properties. The MCR of oxidized intact PTH reported here was markedly reduced compared with nonoxidized hormone. This reduction in MCR was contributed to by decreased uptake rates of PTH both by the liver and the kidney. Thus, these results are compatible with the hypothesis that the rapid metabolic clearance of intact PTH is in part related to uptake at sites specific for biologically active hormone.

The MCR of intact PTH was largely due to hepatic and renal uptake of intact PTH. The sum of the hepatic clearance $(12.0 \pm 0.8 \mathrm{ml} / \mathrm{min}$ per $\mathrm{kg})$ and the renal clearance $(7.2 \pm 0.8 \mathrm{ml} / \mathrm{min}$ per $\mathrm{kg})$ represent $89 \%$ of the MCR of intact PTH in all of the normal dogs studied $(21.6 \pm 3.1 \mathrm{ml} / \mathrm{min}$ per $\mathrm{kg})$. These results are in concert with a low rate of intact PTH uptake by the other major target organ of PTH, the skeleton. In fact, studies using the isolated perfused canine bone (11) and isotopic localization of injected ${ }^{125}$ I-b-PTH $1-84(3,36)$ have revealed low to minimal uptake rates of intact PTH by the skeleton.

Hepatic uptake of intact PTH accounted for the greatest fraction of the MCR of intact PTH. These data are in agreement with previous studies $(3,9,17)$. The results reported here demonstrating high rates of hepatic PTH uptake that are decreased by inactivation of the hormone are compatible with the hypothesis that part of the demonstrated PTH uptake was due to binding to sites specific for biologically active hormone. Hepatic uptake of biologically active PTH is related to the actions of PTH on hepatic glucose and amino acid metabolism (17-19), and thus, it would be expected to be localized in part to cells responsible for these functions, namely hepatocytes. However, the cellular sites of hepatic PTH uptake remain in question. Studies by D'Amour et al. (17), indicate that at $4 \mathrm{~min}$ following injection of intact PTH, the Kupffer cells are the major identifiable site of PTH uptake. At later times, after PTH injection, these authors reported PTH localization to both hepatocytes and Kupffer cells. The dependence of the high rate of hepatic clearance of PTH on its biologic activity may also explain why the hepatic uptake of PTH reported here was greater than previously reported for biologically inactive PTH $(3,17)$. In fact, Neuman et al. (3), using radiolabeled intact PTH by a technique reported to preserve biological activity, demonstrated increasing hepatic PTH uptake associated with increasing biological activity of the hormone.

The renal $\mathrm{a}-\mathrm{v}$ difference for intact PTH reported here of $29 \%$ was significantly higher than the uptake rate, which could be accounted for by glomerular filtration alone. This nonglomerular uptake of PTH may possibly represent binding to PTH-specific receptors. If this were the case, one might expect a decrease in the renal uptake of intact PTH following inactivation of the hormone. In fact, previous investigators (37) have demonstrated lack of PTH binding to renal receptors following oxidation of the hormone. Our results demonstrated a reduction in the renal $\mathbf{a}-\mathbf{v}$ difference for intact PTH from 29 to $20 \%$ following oxidization of the hormone. This value is not different from the filtration fraction and thus largely explainable by glomerular filtration. Thus, it appears that a specific renal uptake mechanism recognizing only biologically active PTH was demonstrable in our current studies.

The effects of CRF on the metabolism of intact PTH were dramatic. There was a marked reduction in the MCR of intact PTH. This was contributed to by a reduction of $38 \%$ in the hepatic a - $v$ difference for intact PTH that resulted in a marked decrease in hepatic clearance of the hormone. This identifies the liver as an extrarenal site of PTH metabolism affected by CRF. It probably identifies the liver as the extrarenal sites of PTH metabolism affected by CRF in our previous studies (5). CRF also decreased the renal clearance of intact PTH. In contrast to our previous report (5), the reduction in renal clearance was due to both a reduction in the $\mathrm{a}-\mathrm{v}$ difference for intact PTH and the reduction in renal plasma flow. Further studies are required to investigate the effect of CRF on the characteristics of PTH receptor binding.

In summary, the studies reported here demonstrate very rapid MCR of intact PTH contributed to chiefly by the liver and the kidney. The rapid total MCR, and the high rate of hepatic and renal uptake appear to be partially dependent on PTH uptake at sites recognizing only biologically active intact PTH. CRF markedly reduced the total MCR of intact PTH by decreasing both extrarenal (hepatic) and renal PTH uptake. Thus, CRF appears to negatively affect uptake rates by the major organs responsible for the metabolism of intact PTH.

\section{ACKNOWLEDGMENTS}

The authors would like to express their appreciation to Ms. Nancy McReynolds and Ms. Margaret Reich for their 
technical assistance and to Ms. Helen Odle for her secretarial assistance.

This work was supported by U. S. Public Health Service National Institute of Arthritis, Metabolism and Digestive Diseases grants Am-09976 and AM-07126.

\section{REFERENCES}

1. Segre, G. V., H. D. Niall, J. F. Habener, and J. T. Potts, Jr. 1974. Metabolism of parathyroid hormone: physiologic and clinical significance. Am. J. Med. 56: 774-784.

2. Canterbury, J. M., and E. Reiss. 1972. Multiple immunoreactive molecular forms of parathyroid hormone in human plasma. Proc. Soc. Exp. Biol. Med. 140: 13931398.

3. Neuman, W. F., M. W. Neuman, K. Lane, L. Miller, and P. J. Sammon. 1975. The metabolism of labeled parathyroid hormone. Calcif. Tissue Res. 18: 271-287.

4. Fang, V. S., and A. H. Tashjian, Jr. 1972. Studies on the role of the liver and the metabolism of parathyroid hormone. Endocrinology. 90: 1177-1184.

5. Hruska, K. A., R. Kopelman, W. E. Rutherford, S. Klahr, and E. Slatopolsky. 1975. Metabolism of immunoreactive parathyroid hormone in the dog. J. Clin. Invest. 56: 39-48.

6. Habener, J. F., G. V. Segre, D. Powell, T. M. Murray, and J. T. Potts, Jr. 1972. Immunoreactive parathyroid hormone in circulation of man. Nat. New Biol. 238: 152-154.

7. Arnaud, C. C., R. S. Goldsmith, P. J. Bordier, and G. W. Sizemore. 1974. Influence of immunoheterogeneity of circulating parathyroid hormone on results of radioimmunoassays of serum in man. Am. J. Med. 56: 785-793.

8. Singer, F. R., G. V. Segre, J. F. Habener, and J. T. Potts, Jr. 1975. Peripheral metabolism of bovine parathyroid hormone in the dog. Metab. Clin. Exp. 24: 139-144.

9. Martin, K., K. Hruska, A. Greenwalt, S. Klahr, and E. Slatopolsky. 1976. Selective uptake of intact parathyroid hormone by the liver. J. Clin. Invest. 58: 781-788.

10. Martin, K., K. Hruska, J. Lewis, C. Anderson, and E. Slatopolsky. 1977. Renal handling of parathyroid hormone. Role of peritubular uptake and glomerular filtration. J. Clin. Invest. 60: 808-814.

11. Martin, K. J., J. J. Freitag, M. B. Conrades, K. A. Hruska, S. Klahr, and E. Slatopolsky. 1978. Selective uptake of the synthetic amino terminal fragment of bovine parathyroid hormone by isolated perfused bone. J. Clin. Invest. 62: 256-261.

12. Kau, S. T., and T. Maack. 1977. Transport and catabolism of parathyroid hormone in isolated rat kidney. Am. J. Physiol. 233: F445-F454.

13. Maack, T., V. Johnson, S. T. Kau, J. Figueiredo, and D. Sigulem. 1979. Renal filtration, transport, and metabolism of low-molecular-weight proteins: a review. Kidney Int. 16: 251-270.

14. Carone, F. A., and D. R. Peterson. 1980. Hydrolysis and transport of small peptides by the proximal tubule. Am.J. Physiol. 238: F151-F158.

15. Silverman, R., and R. S Yalow. 1973. Heterogeneity of parathyroid hormone. Clinical and physiologic implications. J. Clin. Invest. 52: 1948-1971.

16. Hunziker, W. H., J. W. Blum, and J. A. Fischer. 1977. Plasma kinetics of exogenous bovine parathyroid hormone in calves. Pfluegers Arch. Eur. J. Physiol. 371: 185-192.

17. D'Amour, P., G. V. Segre, S. I. Roth, and J. T. Potts, Jr. 1979. Analysis of parathyroid hormone and its fragments in rat tissues. J. Clin. Invest. 63: 89-98.

18. Hruska, K. A., J. Blondin, R. Gass, J. Santiago, L. Thomas,
P. Altsheler, K. Martin, and S. Klahr. 1979. Effect of intact parathyroid hormone on hepatic glucose release in the dog. J. Clin. Invest. 64: 1016-1023.

19. Moxley, M. A., N. H. Bell, S. R. Wagle, D. O. Allen, and J. Ashmore. 1974. Parathyroid hormone stimulation of glucose and urea production in isolated liver cells. Am. J. Physiol. 227: 1058-1061.

20. Cohn, D. V., F. D. Griffith, and R. Levy. 1965. Parathyroid extract-induced changes in the oxidation of citrate, succinate and other organic acids by liver. Endocrinology. 77: 683-691.

21. Shoemaker, W. C., W. F. Walter, T. B. Ban Italie, and F. D. Moore. 1959. A method for simultaneous catheterization of the major hepatic vessels in a chronic canine preparation. Am. J. Physiol. 196: 311-314.

22. Seldinger, S. I. 1953. Catheter replacement of the needle in percutaneous arteriography. A new technique. Acta Radiol. 39: 368-376.

23. Ketterer, S. G., B. D. Wiegand, and E. Rappaport. 1960. Hepatic uptake and biliary excretion of indocyanine green and its use in estimation of hepatic blood flow in dogs. Am. J. Physiol. 199: 481-484.

24. Barrett, P. Q., and W. F. Neuman. 1978. The cleavage and adsorption of parathyroid hormone at high dilution. Biochim. Biophys. Acta. 541: 223-233.

25. Hamilton, J. W., F. W. Spierto, and R. R. McGregor. 1971. Studies on the biosynthesis in vitro of parathyroid hormone: II. The effect of calcium and magnesium on synthesis of parathyroid hormone isolated from bovine parathyroid tissue and incubation medium. J. Biol. Chem. 246: 3224-3233.

26. Freitag, J. J., K. J. Martin, M. B. Conrades, and E. Slatopolsky. 1979. Metabolism of parathyroid hormone by fetal rat calvaria. Endocrinology. 104: 510-516.

27. Reisfield, R. A., M. J. Lewis, and D. E. Williams. 1962. Disc electrophoresis of basic proteins and peptides on polyacrylamide gels. Nature (Lond.). 195: 281-283.

28. Hawk, P. B., B. L. Oser, and W. H. Summerson. 1947. Practical Physiological Chemistry. The Blakiston Co. New York. 12th edition. 506.

29. Harvey, R. B., and A. J. Brothers. 1962. Renal extraction of para-amino-hippurate and creatinine measured by continuous in vivo sampling of arterial and renal-vein blood. Ann. N. Y. Acad. Sci. 102: 46-54.

30. Wolff, A. W. 1950. The urinary function of the kidney. Grune \& Stratton, Inc., New York. 65.

31. Tait, J. F. 1963. Review: The use of isotopic steroids for the measurement of production rates in vivo. J. Clin. Endocrinol. Metab. 23: 1285-1297.

32. Katz, A. I., and A. H. Rubenstein. 1973. Metabolism of proinsulin, insulin, and C-peptide in the rat. J. Clin. Invest. 52: 1113-1121.

33. Barrett, P. Q., A. P. Teitelbaum, and W. F. Neuman. 1978. The heterogeneity of radioiodinated parathyroid hormone in rat plasma. Metab. Bone Dis. Rel. Res. 1: 263-267.

34. Segre, G. V., H. D. Niall, R. T. Sauer, and J. T. Potts, Jr. 1977. Edman degradation of radioiodinated parathyroid hormone: Applications to sequence analysis and hormone metabolism in vivo. Biochemistry. 16: 2417-2427.

35. Potts, J. T., Jr., G. D. Aurbach, L. M. Sherwood, and A. Sandoval. 1965. Structural basis of biological and immunological activity of parathyroid hormone. Biochemistry. 54: 1743-1751.

36. Neuman, W. F., M. W. Neuman, P. J. Sammon, W. Simon, and $\mathrm{K}$. Lane. 1975. The metabolism of labeled parathyroid hormone. III. Studies in rats. Calcif. Tissue Res. 18: $251-261$.

37. Sutcliffe, H. S., T. J. Martin, J. A. Eisman, and R. Pilczyk. 1973. Binding of parathyroid hormone to bovine kidneycortex plasma membranes. Biochem. J. 134: 913-921. 